\title{
Evidence of Sympatric Speciation in Cyathea sinuata Hook. \& Grev. from Lowland Rainforests of Sri Lanka
}

\author{
Ranil R.H.G. ${ }^{1}$, Pushpakumara D.K.N.G. ${ }^{1}$ and Wijesundara D.S.A. ${ }^{2}$ \\ ${ }^{I}$ Department of Crop Science, faculty of Agriculture, University of Peradeniya, \\ Peradeniya, Sri Lanka \\ ${ }^{2}$ Department of National Botanic Gardens, Peradeniya, Sri Lanka \\ *rhgranil@gmail.com
}

\begin{abstract}
The family Cyatheaceae (tree ferns) is represented by a single genus, Cyathea, with eight taxa in Sri Lanka where $75 \%$ are endemic to the island. An endemic Cyathea sinuata Hook. \& Grev. is an unique species because it is the only known simple leaves tree fern among about 600 Cyathea species in the world. An eco-geographic survey was conducted covering all possible natural habitats of all Cyathea species in 12 administrative districts of Sri Lanka during the period of two years. Morphological characters were recorded following the standard developed by Janssen (2006) from a total of 60 individuals of Cyathea species. Twenty two morphological characters used to perform Cluster Analysis. A detail morphological investigation was carried out on 23 individuals of $C$. sinuata and its morphotype collected from Sinharaja and Kanneliya MAB reserves, Runakanda and Beraliya proposed forest reserves (FR) and Hiniduma FR.

Results of cluster analysis and dendrogram revealed that all species were separately grouped. Interestingly, $C$. sinuata is clustered into two sub groups. Sub group I (usual $C$. sinuata) and sub group II (morphologically different form of it). Sub group II can be easily differentiated from usual $C$. sinuata by their dentate leaf margin, irregular or global shape crown with drooping leaves, the number of veinlets, spore arrangement and number of pair of sporangia. Since those variations and current information are not adequate to determine the correct taxonomic status of two sub groups, it is suggested that sub group II may be a morphotype of C. sinuata. It is also suggested that this may be an initial step of the evolutionary process, although this morphotype was observed only from the population of Sinharaja and Kanneliya MAB reserves. Sri Lankan ferns show wide range of morphological variation mainly due to island nature of the country and long period of geological isolation from mainland India. Therefore, continuous monitoring of morphotype of $C$. sinuata within their natural habitats will further reveal information on sympatric speciation.
\end{abstract}

Keywords: Cyathea, Morphotype, Speciation, Eco-geography 